\title{
Effects of Methacrylic Acid on Physical/Mechanical Properties and Biocompatibility of Urethane-Based Denture Biomaterials
}

\author{
Zhengbing Cao ${ }^{1}$, Xinbo Sun ${ }^{1}$, Chih-Ko Yeh ${ }^{2}$, Yuyu Sun ${ }^{1 *}$ \\ ${ }^{1}$ Biomedical Engineering Program, University of South Dakota, Sioux Falls, USA; ${ }^{2}$ Department of Comprehensive Dentistry, Uni- \\ versity of Texas Health Science Center at San Antonio and Geriatric Research, Education and Clinical Center, Audie L. Murphy \\ Division, South Texas Veterans Health Care System, San Antonio, USA. \\ Email: *yuyu.sun@usd.edu
}

Received May $3^{\text {rd }}, 2011$; revised June $8^{\text {th }}, 2011$; accepted June $15^{\text {th }}, 2011$.

\begin{abstract}
Candida-associated denture stomatitis (CADS) is a significant clinical concern. We have demonstrated that urethane-based denture biomaterials with 10\% methacrylic acid (MAA) could bind and then slowly release antifungal drug for months. Drugs on the resins could be repeatedly quenched/recharged, and in subsequent recharging, they could be changed/switched to more potent/effective ones. However, the physical/mechanical properties and biocompatibility of the new MAA-based resins are currently unknown. The objective of the current study is to evaluate the effects of copolymerization with MAA on physical/mechanical properties and biocompatibility of urethane-based denture resin materials. MAA and diurethane dimethacrylate (UDMA) were copolymerized using initiator azobisisobutyronitrile (AIBN). Water sorption and solubility were assessed with the specifications of ISO (International Standards Organization) test method 1567, flexural strength and modulus were measured according to ASTM D-790, and biocompatibility was preliminarily evaluated in cytotoxicity assay using mouse $3 T 3$ fibroblast cells with the trypan blue method. The results demonstrated that copolymerization of UDMA with up to $10 \%$ MAA did not negatively affect water sorption/solubility, flexural strength/modulus, and biocompatibility. With 20\% MAA, however, the mechanical properties of the resulting resins were significantly decreased. To sum up, UDMA-MAA copolymers with up to $10 \%$ MAA had adequate physi$\mathrm{cal} /$ mechanical properties for denture materials with no side effects on cell viability. The UDMA-MAA denture biomaterials have a good potential to be used clinically for managing CADS and other related infectious conditions.
\end{abstract}

Keywords: Antifungal, Denture Biomaterials, Physical Properties, Biocompatibility, Cytotoxicity

\section{Introduction}

Dentures are invaluable to the nutritional intake, speech, appearance, and quality of life of partial or full edentulous patients $[1,2]$. Unfortunately, because of the colonization and biofilm formation of Candida species on denture surfaces [3-5], the use of these prostheses often leads to Candida-associated denture stomatitis (CADS), a non-specific inflammatory reaction to microbial antigens, toxins and enzymes produced by the colonizing microorganisms. CADS is a common, recurring disease that affects up to $67 \%$ of denture wearers [4-7], and can lead to other oral health problems such as caries and periodontal diseases, gastrointestinal and pleuropulmonary infections, compromised quality of life, and even death [8-10]. Management of CADS includes denture cleaning/disinfection, appropriate denture wearing habits/hygiene, use of tissue conditioners/liners, and topi$\mathrm{cal} /$ systemic antifungal therapy $[11,12]$. However, none of these can completely prevent or eliminate Candida colonization and biofilm formation, and the reinfection rate is high, particularly in the elderly and those who are immunocompromised or medically compromised [13-15].

An alternative approach is to impregnate denture biomaterials with antifungal drugs that elute from the device and impair microbial growth [11-13,16,17]. A high antifungal concentration can be achieved (at least initially) in 
the near vicinity of the denture surface, generally exceeding the minimum inhibition concentration (MIC) and minimum fungicidal concentration (MFC) required for susceptible species. However, there are still no antifungal denture materials that are effective for long-term (months to years) use. A primary reason is that the impregnating approaches cannot incorporate enough antifungal agents into dentures to maintain the MIC/MFC near denture surfaces for extended use. Further, the releasing patterns of the impregnated antifungal agents are not optimized: regardless of whether active infection is present, the dentures have a high antifungal release initially, followed by an exponential decrease in the antifungal agents released. After a short period of time (days to weeks), the antifungal agents released do not reach the critical concentrations, and inhibitory effects are lost.

We have developed a rechargeable, "click-on/click -off" technology to extend antifungal duration and control drug release behaviors by copolymerizing methacrylic acid (MAA) with denture resin monomer diurethane dimethacrylate (UDMA). The anionic MAA moieties in the UDMA denture materials acted as a "rechargeable battery" to bind and then slowly release cationic antifungal drugs such as miconazole and chlorhexidine digluconate for weeks to months. The drug-containing denture materials could be "quenched" by treating them with EDTA and recharged with the same or other more potent/effective antifungal drugs to enhance antifungal potency and/or minimize the risk of microbial resistance. MAA-based acrylic denture resins have been investigated to potentially reduce Candida adhesion [16], but no information is available about MAA-containing urethane-based denture biomaterials. We are interested in this system because UDMA-based urethane resins are rapidly gaining popularity as denture base biomaterials. Moreover, UDMA contains two acrylate double bonds, which are expected to allow a high-level of crosslinking of UDMA itself with the acrylate structure of MAA into the denture resins so as to "neutralize" the potential negative effects of MAA on physical/mechanical properties (see Figure 1). The detailed drug binding/drug releasing kinetic studies and antifungal activities of the experimental resins have been reported elsewhere $[18,19]$. The objective of the current study is to evaluate the effects of copolymerization of UDMA with MAA on physi$\mathrm{cal} / \mathrm{mechanical}$ properties and biocompatibility (cytotoxicity) of the urethane-based denture biomaterials.

\section{Experimental}

All the chemicals were purchased from Sigma-Aldrich. Azobisisobutyronitrile (AIBN) was purified by recrystallization from methanol. Bald/c mouse 3T3 fibroblast cells were obtained from American Type Culture Collection (ATCC).

Fabrication of UDMA and UDMA-MAA denture biomaterials: Disc-shaped $(13 \mathrm{~mm}$ in diameter and 1 $\mathrm{mm}$ in thickness) and bar-shaped $(65 \times 10 \times 4 \mathrm{~mm})$ UDMA-MAA denture resins were prepared by free radical copolymerization of MAA with UDMA in aluminum molds. MAA weight percentage in the monomer mixture varied at $0 \%(100 \%$ UDMA controls), 5\%, 10\%, and $20 \%$, and the weight percentage of AIBN was kept at $1 \%$ of the monomer mixture (MAA plus UDMA). Polymerization was carried out in a laboratory heat-curing unit at $70^{\circ} \mathrm{C}$ for $3 \mathrm{~h}$ under $\mathrm{N}_{2}$ gas protection. The specimens were ejected from the mold and visually examined to ensure that they were free of voids.

Water sorption and solubility: The effects of copolymerization of UDMA with MAA on water sorption and solubility of the resulting resins were tested following the specifications of ISO (International Standards Organization) test method 1567. For each MAA content $(0 \%, 5 \%, 10 \%$, and $20 \%)$, disc specimens were stored in a desiccator at $37^{\circ} \mathrm{C} \pm 1^{\circ} \mathrm{C}$ for $23 \mathrm{~h}$. The specimens were then transferred to a second desiccator at $23^{\circ} \mathrm{C} \pm 2^{\circ} \mathrm{C}$ for $1 \mathrm{~h}$ and weighed [20]. The cycles of desiccation (i.e., $37^{\circ} \mathrm{C} \pm 1^{\circ} \mathrm{C}, 23 \mathrm{~h}$ and $23^{\circ} \mathrm{C} \pm 2^{\circ} \mathrm{C}, 1 \mathrm{~h}$ ) were repeated until the weight reached a constant mass $\left(\mathrm{m}_{1}\right)$. The weight $\left(\mathrm{m}_{1}\right)$ of the dried specimen was determined using an electronic scale. Thickness and diameter of the specimens were measured using a digital caliper, rounded to the nearest $0.01 \mathrm{~mm}$, and these measurements were used to calculate the volume $\left(\mathrm{mm}^{3}\right)$ of each specimen. The dried specimens were immersed in distilled water at $37^{\circ} \mathrm{C}$ $\pm 1^{\circ} \mathrm{C}$ for 7 days, and then dried with a clean towel and weighed again $\left(\mathrm{m}_{2}\right)$. The difference in weights $\mathrm{m}_{2}$ and $\mathrm{m}_{1}$ divided by the volume of the specimen was defined as the amount of water absorbed $\left(\mu \mathrm{g} / \mathrm{mm}^{3}\right)$ [20,21]. Following the weighing for sorption, the specimens were dried to a constant mass $\left(\mathrm{m}_{3}\right)$ using the protocol previously described for $m_{1}$ determination. The value $m_{3}$ was subtracted from $\mathrm{m}_{1}$, and divided by the volume of the specimen. The value obtained represented the solubility of the specimens $\left(\mu \mathrm{g} / \mathrm{mm}^{3}\right)$. Data was analyzed with 1-way ANOVA followed by post-hoc Bonferroni tests.

Mechanical properties of the denture biomaterials: Bar-shaped denture biomaterials were immersed in distilled water at $37^{\circ} \mathrm{C}$ for 60 days before evaluation for mechanical properties. The flexural strength and modulus of the specimens were measured according to ASTM D-790 with a mechanical testing system (MTS 370, MTS Systems Corp., MN, USA). The distance between the specimen supports was set at $50 \mathrm{~mm}$. The loading force was applied to the specimen at a cross-head speed of 5 
$\mathrm{mm} / \mathrm{min}$ until the specimen fractured [22-24]. Data was analyzed with 1-way ANOVA followed by post-hoc Bonferroni tests.

Effects of the denture biomaterials on mammal cell viability: Biocompatibility of the new denture biomaterials was preliminarily evaluated with the cytotoxicity assay using the trypan blue dye exclusion method [25]. The disc samples were sterilized with UV and placed into a 96-well plate. The bald/c mouse 3T3 fibroblast cells were cultured in DMEM/high glucose medium supplemented with $10 \%$ fetal bovine serum at $37^{\circ} \mathrm{C}$ in a humidified air atmosphere with $5 \% \mathrm{CO}_{2}$. Cells $\left(1.25 \times 10^{4}\right)$ were seeded in each well containing a disc of the denture materials in $200 \mu \mathrm{L}$ of the medium. Disc-free wells were also seeded with the cells to serve as controls. After culturing for one and three days, the cells on the plate and denture materials were trypsinized and exposed for $5 \mathrm{~min}$ to $0.2 \%$ trypan blue solution (diluted from $0.4 \%$ solution; Sigma-Aldrich). The numbers of stain-positive (dead and dying cells) and stain-negative cells in each culture were counted in a hemocytometer chamber. The data were analyzed with Student's t-test for statistical significance [25].

\section{Results and Discussion}

Antifungal denture biomaterials have been reported in a number of studies [11-13,16,17]. However, the antifungal action of those dentures is short-lived (days to weeks), and there are still no antifungal denture materials that can provide long-term (months to years) infection-responsive protection against CADS. We have developed a rechargeable, "click-on/click-off" technology to extend antifungal duration and control drug release behaviors by copolymerizing MAA with UDMA $[18,19]$. In this study, we investigated the effects of copolymerization with MAA on water sorption/solubility, mechanical properties and biocompatibility (cytotoxicity) of the UDMA-base new denture biomaterials.

\subsection{Water Sorption and Solubility}

UDMA resins are hydrophobic polymers with low water sorption and solubility, which are desirable physical properties for denture biomaterials. On the other hand, MAA is a hydrophilic monomer with a high polarity and high tendency of water sorption. However, in our study, copolymerizing UDMA with up to $20 \%$ MAA did not have significant effects on water sorption and solubility (Table 1). Without MAA, the pure UDMA resin control showed a water sorption value of $28.95 \pm 3.25 \mu \mathrm{g} / \mathrm{mm}^{3}$, and a water solubility value of $22.83 \pm 2.81 \mu \mathrm{g} / \mathrm{mm}^{3}(\mathrm{n}=$ $5)$. These physical parameters were not significantly affected by copolymerization with $5 \%-20 \%$ of MAA into
UDMA. These results could be attributable to the high crosslinking capability of UDMA that contains two acrylate groups. The small amount of MAA in the cured UMDA has no profound interruption of the highly crosslinked network (Figure 1). This crosslinked network could restrict the access of water molecules and reduce the extent of swelling so as to "neutralize" the potential increase effect in water sorption/solubility caused by MAA. According to the ISO test method 1567 (Dentistry-Denture base polymers), water sorption of the denture base materials should not exceed $32 \mathrm{mg} / \mathrm{mm}^{3}$, and the soluble substances eluted during storage in water should not exceed $1.6 \mathrm{mg} / \mathrm{mm}^{3}$. The water absorption and solubility values of the control denture biomaterials ( $100 \%$ of UDMA) and the experimental denture biomaterials (UDMA-MAA copolymers; MAA content: 5\% $20 \%$ ) were much lower than these upper limits (Table 1).

\subsection{Mechanical Properties}

Flexural strength and modulus are among the most important mechanical properties of denture biomaterials. The effects of copolymerization with MAA on flexural strength and modulus of the new denture materials are shown in Table 2. Under our experimental conditions, the UDMA resin control had a flexural strength of 112.4 $\pm 2.67 \mathrm{Mpa}$, and a flexural modulus of $2.43 \pm 0.16 \mathrm{Gpa}$. No significant effects on flexural strength and modulus were observed with up to $10 \%$ MAA in the new denture biomaterials. However, the copolymer of $20 \%$ MAA with UDMA was too brittle/weak for practical use and was not tested. The American Dental Association specification No. 12 sets the minimum values of flexural strength and flexural modulus for denture base materials at $65 \mathrm{MPa}$ and $2 \mathrm{GPa}$, respectively. Both the control biomaterial (100\% of UDMA) and the experimental biomaterials with up to $10 \%$ MAA meet these requirements.

\subsection{Cell Viability}

Biocompatibility of the new denture biomaterials was preliminarily assessed with cytotoxicity assay (Table 3).
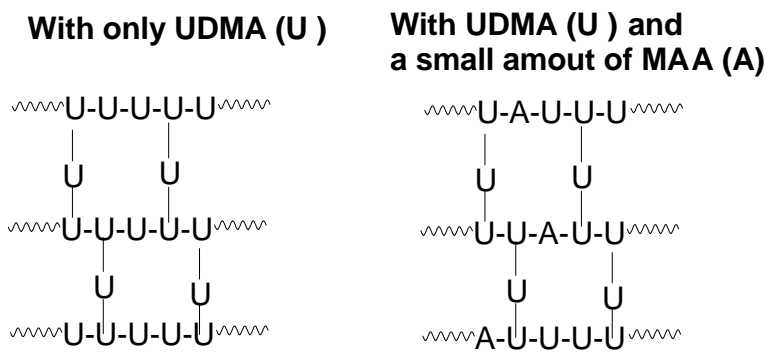

Figure 1. Crosslinked networks in the denture biomaterials 
Table 1. Water sorption $\left(W_{\text {sp }}\right)$ and water solubility $\left(W_{\text {sl }}\right)$ of the UDMA-MAA copolymers $(n=5)$.

\begin{tabular}{crc}
\hline MAA content in the copolymer & $\mathrm{W}_{\mathrm{sp}} \pm \mathrm{SD}\left(\mu \mathrm{g} / \mathrm{mm}^{3}\right)$ & $\mathrm{W}_{\mathrm{sl}} \pm \mathrm{SD}\left(\mu \mathrm{g} / \mathrm{mm}^{3}\right)$ \\
\hline $0 \%$ & $28.95 \pm 3.25$ & $22.83 \pm 2.81$ \\
$5 \%$ & $29.15 \pm 2.52$ & $23.03 \pm 2.42$ \\
$10 \%$ & $29.24 \pm 4.65$ & $23.81 \pm 2.31$ \\
$20 \%$ & $30.43 \pm 2.27$ & $24.58 \pm 3.35$ \\
\hline
\end{tabular}

Table 2. Flexural strength and modulus of the UDMA-MAA copolymers $(n=5) *$.

\begin{tabular}{ccc}
\hline MAA content in the copolymers & Flexural Strength (Mpa) (Means \pm SD) & $\begin{array}{c}\text { Flexural Modulus (Gpa) } \\
\text { (Means } \pm \text { SD) }\end{array}$ \\
\hline $0 \%$ & $112.4 \pm 2.67$ & $2.43 \pm 0.16$ \\
$5 \%$ & $113.1 \pm 3.23$ & $2.41 \pm 0.19$ \\
$10 \%$ & $109.1 \pm 3.07$ & $2.39 \pm 0.21$ \\
\hline *: Copolymers with 20\% MAA were too weak that could be easily broken by hands, which were removed from mechanical testing.
\end{tabular}

Table 3. Cell viability with bald/c mouse 3T3 fibroblast cells in the trypan blue assay.

\begin{tabular}{ccc}
\hline Samples & $\begin{array}{c}\text { \% of undamaged cells after 1 Day } \\
\text { (Means } \pm \text { SD) }\end{array}$ & $\begin{array}{c}\text { \% of undamaged cells after 3 Days } \\
\text { (Means } \pm \text { SD) }\end{array}$ \\
\hline Cell-only control & $98.2 \pm 7.7$ & $94.8 \pm 6.4$ \\
Pure UDMA & $90.1 \pm 5.8$ & $92.1 \pm 5.3$ \\
UDMA with 5\% MAA & $87.3 \pm 8.7$ & $89.4 \pm 5.9$ \\
UDMA with 10\% MAA & $89.2 \pm 6.2$ & $90.9 \pm 2.0$ \\
UDMA with 20\% MAA & $86.7 \pm 8.2$ & $82.4 \pm 8.4$ \\
\hline
\end{tabular}

As demonstrated by the trypan blue assay, the viability of bald/c mouse 3T3 fibroblast cells was not significantly affected by the presence of $5 \%$ or $10 \%$ MAA even after 3 days of continuous contact. Of all the cells exposed to the MAA-based resins, only a few had trypan blue-stained nuclei (indicating cell death), and when viewed by phase-contrast microscopy, the stained cells were of the same size and shape as the unstained cells (images not shown). Cultures exposed to UDMA discs with $20 \%$ MAA had slightly higher percentage of damaged cells, but the differences were not statistically significant. These findings are not surprising because the UDMA-based biomaterials are currently used as denture base materials. The MAA-based polymers are the major components of dental glass-ionomer cements [26-29] and have been successfully used as biocompatible and bioadhesive carriers for controlled release of drugs, peptides, and proteins [30-32]. Furthermore, MAA is covalently bound onto the denture biomaterials so that it does not diffuse away from the denture materials. All these factors may contribute to the very low cytotoxic effect of the newly formulated denture biomaterials.

\section{Conclusions}

In conclusion, this study showed that copolymerization with up to $10 \%$ MAA has no detrimental effect on the physical/mechanical properties and biocompatibility (cytotoxicity) of the UDMA-based new denture biomaterials. Our previous studies have demonstrated that UDMA biomaterials with $10 \%$ MAA could provide sustained antifungal drug release for a long period of time (weeks to months), drugs in the biomaterials could be repeatedly quenched/recharged, and in subsequent recharging, drugs could be changed/switched to more potent/effective ones $[18,19]$. Thus, the antifungal medication on the UDMA-MAA denture materials could be added or removed ("click-on/click-off") based on the presence or absence of Candida infection. The results from the current study provided additional information about the physical/mechanical properties and biocompatibility (cytotoxicity), further suggesting the clinical potential of the UDMA-MAA experimental denture biomaterials for clinical applications. Our future studies will move to animal model tests and clinical trials to further evaluate the safety, effectiveness, and costeffective- ness of the new rechargeable, infectionresponsive antifungal denture materials for managing CADS, a significant clinical concern, particularly for the elderly and the immunocompromised/medically compromised patients. 


\section{Acknowledgements}

This study was sponsored by NIH, NIDCR (Grant number R03 DE018735).

\section{REFERENCES}

[1] L. F. Perezous, C. M. Flaitz, M. E. Goldschmidt and R. L. Engelmeier, "Colonization of Candida Species in Denture Wearers with Emphasis on HIV Infection: A Literature Review," Journal of Prosthetic Dentistry, Vol. 93, No. 3, 2005, pp. 288-293. doi:10.1016/j.prosdent.2004.11.015

[2] C. W. Douglass, A. Shih and L. Ostry, "Will There Be a Need for Complete Dentures in the United States in 2020?" Journal of Prosthetic Dentistry, Vol. 87, No. 1, 2002, pp. 5-8. doi:10.1067/mpr.2002.121203

[3] A. M. Iacopino and W. F. Wathen, "Oral Candidal Infection and Denture Stomatitis-a Comprehensive Review," The Journal of the American Dental Association, Vol. 123, No. 1, 1992, pp. 46-51.

[4] T. M. Arendorf and D. M. Walker, "Denture Stomatitis: a Review," Journal of Oral Rehabilitation, Vol. 14, No. 3, 1987, pp. 217-227.

doi:10.1111/j.1365-2842.1987.tb00713.x

[5] E. Budtz-Jorgensen, "The Significance of Candida Albicans in Denture Stomatitis," Scandinavian Journal of Dental Research, Vol. 82, No. 2, 1974, pp. 151-190.

[6] D. R. Radford, S. J. Challacombe and J. D. Walter, "Denture Plaque and Adherence of Candida Albicans to Denture-base Materials in Vivo and in Vitro," Critical Reviews in Oral Biology \& Medicine, Vol. 10, No. 1, 1999, pp. 99-116. doi:10.1177/10454411990100010501

[7] B. C. Webb, C. J. Thomas, M. D. Willcox, D. W. Harty and K. W. Knox, "Candida-associated Denture Stomatitis. Aetiology and Management: a Review. Part 1. Factors Influencing Distribution of Candida Species in the Oral Cavity," Australian Dental Journal, Vol. 43, No. 1, 1998, pp. 45-50. doi:10.1111/j.1834-7819.1998.tb00152.x

[8] I. Olsen, "Denture stomatitis. Occurrence and Distribution of Fungi," Acta Odontologica Scandinavica, Vol. 32, No. 5, 1974, pp. 329-333. doi:10.3109/00016357409002556

[9] G. Ramage, K. Tomsett, B. L. Wickes, J. L. Lopez-Ribot, and S. W. Redding, "Denture Stomatitis: a Role for Candida Biofilms," Oral Surgery, Oral Medicine, Oral Pathology, Oral Radiology \& Endodontics, Vol. 98, No. 1, 2004, pp. 53-59. doi:10.1016/j.tripleo.2003.04.002

[10] M. Golecka, U. Oldakowska-Jedynak, E. MierzwinskaNastalska and E. Adamczyk-Sosinska, "Candida-asociated Denture Stomatitis in Patients after Immunosuppression Therapy," Transplantation Proceedings, Vol. 38, No. 1, 2006, pp. 155-156. doi:10.1016/j.transproceed.2005.12.078

[11] C. A. Lefebvre, J. C. Wataha, R. M. Cibirka, G. S. Schuster and G. R. Parr, "Effects of Triclosan on the Cytotoxicity and Fungal Growth on a Soft Denture Liner,"
Journal of Prosthetic Dentistry, Vol. 85, No. 4, 2001, pp. 352-356. doi: $10.1067 / \mathrm{mpr} .2001 .115249$

[12] C. K. Chow, D. W. Matear and H. P. Lawrence, "Efficacy of Antifungal Agents in Tissue Conditioners in Treating Candidiasis," Gerodontology, Vol. 16, No. 2, 1999, pp. 110-118. doi:10.1111/j.1741-2358.1999.00110.x

[13] Y. Abe, M. Ishii, M. Takeuchi, M. Ueshige, S. Tanaka and Y. Akagawa, "Effect of Saliva on an Antimicrobial Tissue Conditioner Containing Silver-zeolite," Journal of Oral Rehabilitation, Vol. 31, No. 6, 2004, pp. 568-573. doi:10.1111/j.1365-2842.2004.01267.x

[14] C. Scully and G. McCarthy, "Management of Oral Health in Persons with HIV Infection," Oral Surgery, Oral Medicine, Oral Pathology, Oral Radiology, and Endodontology, Vol. 73, No. 2, 1992, pp. 215-225.

[15] J. A. Phelan, B. R. Saltzman, G. H. Friedland and R. S. Klein, "Oral Findings in Patients with Acquired Immunodeficiency Syndrome," Oral Surgery, Oral Medicine, Oral Pathology, Oral Radiology and Endodontology, Vol. 64, No. 1, 1987, pp. 50-56.

[16] S. E. Park, R. Blissett, S. M. Susarla and H. P. Weber, "Candida Albicans Adherence to Surface-modified Denture Resin Surfaces," Journal of Prosthodontics, Vol. 17, No. 5, 2008, pp. 365-369. doi:10.1111/j.1532-849X.2007.00292.x

[17] D. M. Lin, S. Kalachandra, J. Valiyaparambil and S. Offenbacher, "A Polymeric Device for Delivery of Anti-microbial and Anti-Fungal Drugs in the Oral Environment: Effect of Temperature and Medium on the Rate of Drug Release," Dental Materials, Vol. 19, No. 7, 2003, pp. 589-596. doi:10.1016/S0109-5641(02)00109-4

[18] Z. Cao, X. Sun, C-K. Yeh andY. Sun, "Polyacrylic Acid Based Rechargeable Long-term Antifungal Denture Materials," The 39th AADR Annual Meeting \& Exhibition, Washington DC, 3-6 March 2010.

[19] Z. Cao, X. Sun, C-K. Yeh and Y. Sun, "Rechargeable Infection-Responsive Antifungal Denture Materials," Journal of Dental Research, Vol. 89, No. 12, 2010, pp. 1517-1521. doi:10.1177/0022034510379604

[20] S. H. Tuna, F. Keyf, H. O. Gumus and C. Uzun, "The Evaluation of Water Sorption/Solubility on Various Acrylic Resins," European Journal of Dentistry, Vol. 2, No. 3, 2008, pp. 191-197.

[21] U. Ortengren, H. Wellendorf, S. Karlsson and I. E. Ruyter, "Water Sorption and Solubility of Dental Composites and Identification of Monomers Released in an Aqueous Environment," Journal of Oral Rehabilitation, Vol. 28, No. 12, 2001, pp. 1106-1115. doi:10.1046/j.1365-2842.2001.00802.x

[22] N. Beyth, I. Yudovin-Farber, R. Bahir, A. J. Domb and E. I. Weiss, "Antibacterial Activity of Dental Composites Containing Quaternary Ammonium Polyethylenimine Nanoparticles against Streptococcus Mutans," Biomaterials, Vol. 27, No. 21, 2006, pp. 3995-4002. doi:10.1016/j.biomaterials.2006.03.003

[23] G. Dhir, D. W. Berzins, V. B. Dhuru, A. R. Periathamby 
and A. Dentino, "Physical Properties of Denture Base Resins Potentially Resistant to Candida Adhesion," Journal of Prosthodontics, Vol. 16, No. 6, 2007, pp. 465-472. doi:10.1111/j.1532-849X.2007.00219.x

[24] P. Pfeiffer and E. U. Rosenbauer, "Residual Methyl Methacrylate Monomer, Water Sorption, and Water Solubility of Hypoallergenic Denture Base Materials," Journal of Prosthetic Dentistry, Vol. 92, No. 1, 2004, pp. 72-78. doi:10.1016/j.prosdent.2004.04.003

[25] Y. S. Chang, C. L. Wu, S. H. Tseng, P. Y. Kuo and S. Y. Tseng, "Cytotoxicity of Triamcinolone Acetonide on Human Retinal Pigment Epithelial Cells," Investigative Ophthalmology \& Visual Science, Vol. 48, No. 6, 2007, pp. 2792-2798. doi:10.1167/iovs.06-1146

[26] T. J. Fruits, T. L. Coury, F. J. Miranda and M. G. Jr. Duncanson, "Uses and Properties of Current Glass Ionomer Cements: A Review," General Dentistry, Vol. 44, No. 5, 1996, pp. 410-418.

[27] J. W. Nicholson, "Chemistry of Glass-Ionomer Cements: A Review," Biomaterials, Vol. 19, No. 6, 1998, pp. 485494. doi:10.1016/S0142-9612(97)00128-2

[28] G. J. Mount, "Glass Ionomers: A Review of Their Current Status," Operative Dentistry, Vol. 24, No. 2, 1999, pp. 115-124.
[29] M. A. A. De Bruyne and R. J. G. De Moor, "The Use of Glass Ionomer Cements in both Conventional and Surgical Endodontics," International Endodontic Journal, Vol. 37, No. 2, 2004, pp. 91-104. doi:10.1111/j.0143-2885.2004.00769.x

[30] R. Ghavamzadeh, V. Haddadi-Asl and H. Mirzadeh, "Bioadhesion and Biocompatibility Evaluations of Gelatin and Polyacrylic Acid as a Crosslinked Hydrogel in Vitro," Journal of Biomaterials Science, Polymer Edition, Vol. 15, No. 8, 2004, pp. 1019-1031. doi: $10.1163 / 1568562041526478$

[31] X. Yan and R. A. Gemeinhart, "Cisplatin Delivery from Poly(Acrylic Acid-co-methyl Methacrylate) Microparticles," Journal of Controlled Release, Vol. 106, No. 1-2, 2005, pp. 198-208. doi:10.1016/j.jconrel.2005.05.005

[32] M. Bohner, J. Lemaître, H. P. Merkle and B. Gander, "Control of Gentamicin Release from a Calcium Phosphate Cement by Admixed Poly(Acrylic Acid)," Journal of Pharmaceutical Sciences, Vol. 89, No. 10, 2000, pp. 1262-1270. doi:10.1002/1520-6017(200010)89:10<1262::AID-JPS4> 3.0.CO;2-7 